\title{
Whole-exome sequencing identified a missense mutation in WFS1 causing low- frequency hearing loss: a case report
}

Hye Ji Choi ${ }^{1 \dagger}$, Joon Suk Lee ${ }^{2 \dagger}$, Seyoung Yu ${ }^{2}$, Do Hyeon Cha ${ }^{2}$, Heon Yung Gee ${ }^{2}$, Jae Young Choi ${ }^{1}$, Jong Dae Lee ${ }^{3^{*}}$ and Jinsei Jung ${ }^{1,4^{*}}$ (D)

\begin{abstract}
Background: Low-frequency nonsyndromic hearing loss (LF-NSHL) is a rare, inherited disorder. Here, we report a family with LF-NSHL in whom a missense mutation was found in the Wolfram syndrome 1 (WFS1) gene.

Case presentation: Family members underwent audiological and imaging evaluations, including pure tone audiometry and temporal bone computed tomography. Blood samples were collected from two affected and two unaffected subjects. To determine the genetic background of hearing loss in this family, genetic analysis was performed using whole-exome sequencing. Among 553 missense variants, c.2419A $\rightarrow$ C (p.Ser807Arg) in WFS1 remained after filtering and inspection of whole-exome sequencing data. This missense mutation segregated with affected status and demonstrated an alteration to an evolutionarily conserved amino acid residue. Audiological evaluation of the affected subjects revealed nonprogressive LF-NSHL, with early onset at 10 years of age, but not to a profound level.

Conclusion: This is the second report to describe a pathological mutation in WFS1 among Korean patients and the second to describe the mutation in a different ethnic background. Given that the mutation was found in independent families, p.S807R possibly appears to be a "hot spot" in WFS1, which is associated with LF-NSHL.
\end{abstract}

Keywords: WFS1, Low-frequency hearing loss, Nonsyndromic hearing loss, Autosomal dominant

\section{Background}

Hearing loss is a common sensory disorder in humans and is caused by genetic mutations in more than $60 \%$ of cases. According to the Hereditary Hearing Loss Homepage (http://hereditaryhearingloss.org), autosomal dominant, nonsyndromic hearing loss is known to be associated with 59 genetic loci. Among these loci, which are designated DFNA (DFN=deafness; $\mathrm{A}=$ dominant), DFNA6, DFNA14, and DFNA38 are associated with lowfrequency nonsyndromic sensorineural hearing loss (LF-

\footnotetext{
*Correspondence: ljdent@schmc.ac.kr; jsjung@yuhs.ac

${ }^{\dagger}$ Equal contributors

${ }^{3}$ Department of Otorhinolaryngology, Soonchunhyang University College of Medicine, Bucheon, South Korea

'Department of Otorhinolaryngology, Brain Korea 21 PLUS Project for Medical Sciences, Yonsei University College of Medicine, Seoul 03722, South Korea

Full list of author information is available at the end of the article
}

NSHL) and caused by a heterozygous mutation in the Wolfram syndrome 1 (WFS1) gene [1, 2].

WFS1 is located on human chromosome 4p16.1, and the eight exons of WFS1 encode a transmembrane protein. Exon 1 is noncoding, and exon 8 is the largest, containing $2.6 \mathrm{~kb}$ of DNA. Most mutations in WFS1 have been identified in exon 8 and, moreover, in exons $3,4,5$, and 6-8. The WFS1 gene encodes wolframin, an 890-amino acid protein with an estimated molecular mass of $100 \mathrm{kDa}$. Wolframin is abundantly expressed in the pancreas, brain, heart, and muscle and is a hydrophobic and tetrameric protein with nine transmembrane domains and large hydrophilic regions at both ends [3, 4]. Mutations in WFS1 are associated with autosomal recessive Wolfram syndrome and the autosomal dominant type of LF-NSHL (DFNA6/14/38). Wolfram syndrome has been identified in patients with 
diabetes insipidus, diabetes mellitus, optic atrophy, and hearing loss [5].

Using whole-exome sequencing (WES), we examined a Korean family (Yonsei University Hearing Loss [YUHL] 30) and identified a missense mutation, c.2419A $\rightarrow C$ (p.Ser807Arg), in the WFS1 gene. In members of the pedigree, the mutation led to nonsyndromic autosomal dominant, symmetrically bilateral hearing loss at low-tomid frequencies.

\section{Case presentation}

With approval from the Institutional Review Board of the Severance Hospital, Yonsei University (Seoul, South Korea) Health System (IRB\#4-2015-0659), subjects with inherited hearing loss were enrolled in the YUHL cohort. After obtaining written informed consent, two affected and two unaffected subjects in the YUHL30 family were investigated. The pedigree of the YUHL30 family is shown in Fig. 1a. All affected subjects exhibited sensorineural hearing loss but no other syndromic phenotypes. The blood sugar levels of the subjects were within the normal range, and no subjects showed clinical symptoms suggesting diabetes mellitus or insipidus. In addition, the affected subjects had normal vision and no optic atrophy in ophthalmic evaluations. The proband 30-22 exhibited nonsyndromic autosomal dominant hearing loss at lowto-mid frequencies, of which the pure-tone threshold averages of 500,1000, 2000, and $4000 \mathrm{~Hz}$ were 41 and $36 \mathrm{~dB} \mathrm{HL}$ in the right and left ears, respectively (Fig. 1b). The hearing loss was symmetrically bilateral and was mild to moderate in severity. In speech audiometry, the word recognition score was $100 \%$ for both ears. In impedance audiometry, both drums were type A (compliance was $0.5 \mathrm{~cm}$ for both ears). In temporal bone CT scans, there were no inner ear anomalies or middle ear deformities (Fig. 1c). The mother of subject 30-22 (30-12) was also affected and exhibited a moderate level of bilateral sensorineural hearing loss at low-to-mid frequencies. The onset of hearing loss occurred at approximately 10 years of age in both subjects (30-22 and 30-12). While hearing function at frequencies between 2000 and $8000 \mathrm{~Hz}$ was well preserved, the hearing threshold was increased up to 50-60 dB HL at frequencies of $2000 \mathrm{~Hz}$ or less in the two affected subjects. Notably, it did not appear that hearing loss was progressive, since $30-12$ (45 years of age) exhibited a degree and pattern of hearing loss similar to 30-22 (14 years of age).

To identify the genetic cause of hearing loss in this family, WES was performed for 30-22, from whom DNA samples were available. DNA preparation, WES, sequence alignment, and variant calling were performed as previously reported [6]. Based on the pedigree and the fact that the affected individuals were a parent and her child, autosomal dominant hearing loss was assumed (Fig. 1a). There were 622 variants which were

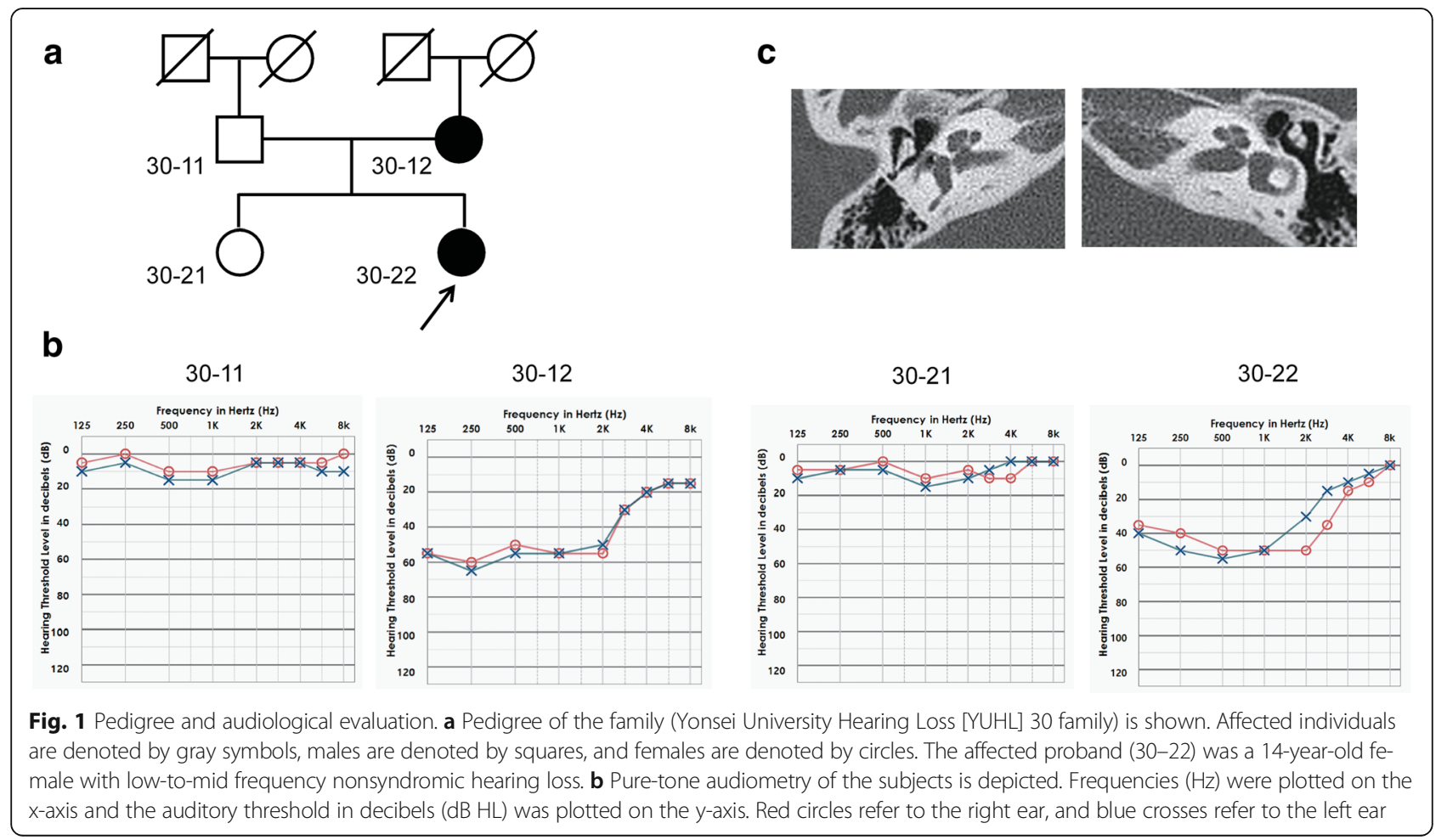


Table 1 Filtering process of whole exome sequencing analysis in this study

\begin{tabular}{ll}
\hline Patient (30-22) & \\
\hline Total sequence reads & $93,205,604$ \\
Matched Reads (percentage of reads) & $91,298,272$ (97.95\%) \\
Total number of variants detected & 187,202 \\
Variants which are not common & 37,206 \\
dbSNP138 (MAF > 1\%) (A) & \\
Variants which are not present in & 9487 \\
32 control of healthy individuals & \\
Variants which are nonsynonymous & 622 \\
or located in splice junction (B) & \\
\% B / A & $1.67 \%$ \\
Located within splice site & 31 \\
Deletion/Insertion & 33 \\
Stop codon gained / Stop codon & 5 \\
lost & \\
Missense & 553 \\
SNPs after inspection of MAF \\
$<0.05 \%$ amino acid conservation \\
Located within splice site \\
Deletion/Insertion \\
Stop codon gained / Stop codon lost \\
Missense \\
Variant in 129 genes known to deafness \\
genes \\
Sanger confirmation / Segregation \\
Causative mutation & 168 \\
\hline
\end{tabular}

nonsynonymous or located in a splice site; a variant in WFS1 (c.2419A $\rightarrow$ C; p.Ser807Arg) remained after filtering and inspection of WES data (Tables 1 and 2). This variant was a missense mutation and not found in public databases, such as dbSNP (http://www.ncbi.nlm.nih.gov/ projects/SNP/) or gnomAD, for the affected status. Additionally, this mutation was associated with an alteration in an amino acid residue that has been well conserved throughout evolution from Mus musculus, Gallus gallus, Xenopus tropicalis, and Danio rerio (Table 2, Fig. 2a, b). Mutations in WFS1 are known to cause autosomal dominant deafness (MIM 600965) [7]. The p.S807R mutation has been reported once in the United Kingdom but not in other counties, including Korea [7].

\section{Discussion and conclusions}

In the present study, we used WES to successfully identify a mutation in WFS1 causing the autosomal dominant type of sensorineural hearing loss.

To date, more than 250 mutations in the WFS1 gene have been reported worldwide (http://www.hgmd.cf.ac.uk/ac/index.php). Mutations in the WFS1 gene are responsible for both Wolfram syndrome and autosomal dominant, nonsyndromic hearing loss (DFNA6/14/38) $[1,8,9]$. Wolfram syndrome is an autosomal recessive type disorder associated with diabetes mellitus, diabetes insipidus, optic atrophy, and hearing loss. In nonsyndromic hearing loss, DFNA6/14/38 leads to LFNSHL. According to the literature, there are two known genes responsible for low-frequency hearing loss: DIAPH1 and WFS1 [7]. Mutations in DIAPH1 lead to progressive hearing loss and profound bilateral deafness involving all frequencies. However, mutations in WFS1 cause progressive hearing loss, but only at low frequencies and not until profound hearing loss in the case of nonsyndromic hearing loss $[10,11]$. In the present study, p.S807R was also associated with LF-NSHL, with moderate severity at $60 \mathrm{~dB}$ HL. This audiological feature is unique only in hearing loss associated with mutations in WFS1; thus, screening of WFS1 is a reasonable first step in cases of suspected LF-NSHL without progression to a profound level.

Our description of the p.S807R $\quad($ c.2419A $\rightarrow$ C) mutation in WFS1 is the second report of a mutation associated with LF-NSHL in Korean patients; the first report was the p.V412A mutation in WFS1 [12].

Table 2 Mutation candidates identified by whole exome sequencing

\begin{tabular}{|c|c|c|c|c|c|c|c|c|c|c|c|c|}
\hline $\begin{array}{l}\text { Gene } \\
\text { Symbol }\end{array}$ & Individual & Sex & $\begin{array}{l}\text { Nucleotide } \\
\text { change }^{a}\end{array}$ & $\begin{array}{l}\text { Amino acid } \\
\text { change }\end{array}$ & $\begin{array}{l}\text { Exon } \\
\text { (zygosity, } \\
\text { segregation) }\end{array}$ & $\begin{array}{l}\text { Amino acid } \\
\text { sequence } \\
\text { conservation }^{b}\end{array}$ & $d b S N P^{c}$ & gnom $A D^{d}$ & $\mathrm{PP}^{\mathrm{e}}$ & $M T^{f}$ & PROVEAN $^{g}$ & $\mathrm{SIFT}^{\mathrm{h}}$ \\
\hline WFS1 & $30-22$ & $\mathrm{~F}$ & $\begin{array}{l}\text { c.2419A > } \\
C\end{array}$ & p.Ser807Arg & 8 (het, Mo) & $\begin{array}{l}\text { M. musculus, G. } \\
\text { gallus, X. tropicalis, } \\
\text { D. rerio }\end{array}$ & ND & ND & $\begin{array}{l}\text { Possibly } \\
\text { Dam } \\
\text { (0.890) }\end{array}$ & $\begin{array}{l}\text { DC } \\
(0.999)\end{array}$ & $\begin{array}{l}\text { Del } \\
(-2.75)\end{array}$ & $\begin{array}{l}\text { Dam } \\
(0.012)\end{array}$ \\
\hline
\end{tabular}

Dam damaging, $D C$ disease causing, Del deleterious; het, heterozygous in affected individual, MAF minor allele frequency, $F$ Female, Mo heterozygous mutation identified in mother, ND no data or DNA available, SNP single nucleotide polymorphism, D. rerio Danio rerio, G. gallus Gallus gallus, M. musculus Mus musculus, X.tropicalis Xenopus tropicalis

${ }^{a}$ Complementary DNA (cDNA) mutations are numbered according to human cDNA reference sequence NM_006005.3 (WFS1);

${ }^{\mathrm{b}}$ Amino acid residue is continually conserved throughout evolution, including the species indicated;

'dbSNP database (http://www.ncbi.nlm.nih.gov/SNP);

${ }^{d}$ gnomAD browser (gnomad.broadinstitute.org/);

ePolyPhen-2 (PP2) prediction score (HumVar), ranges from 0 to $1.0(0=$ benign, $1.0=$ probably damaging [http://genetics.bwh.harvard.edu/pph2/]);

fMutation taster (http://www.mutationtaster.org/);

gProtein Variation Effect Analyzer (PROVEAN; http://provean.jcvi.org/index.php);

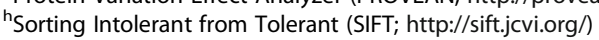




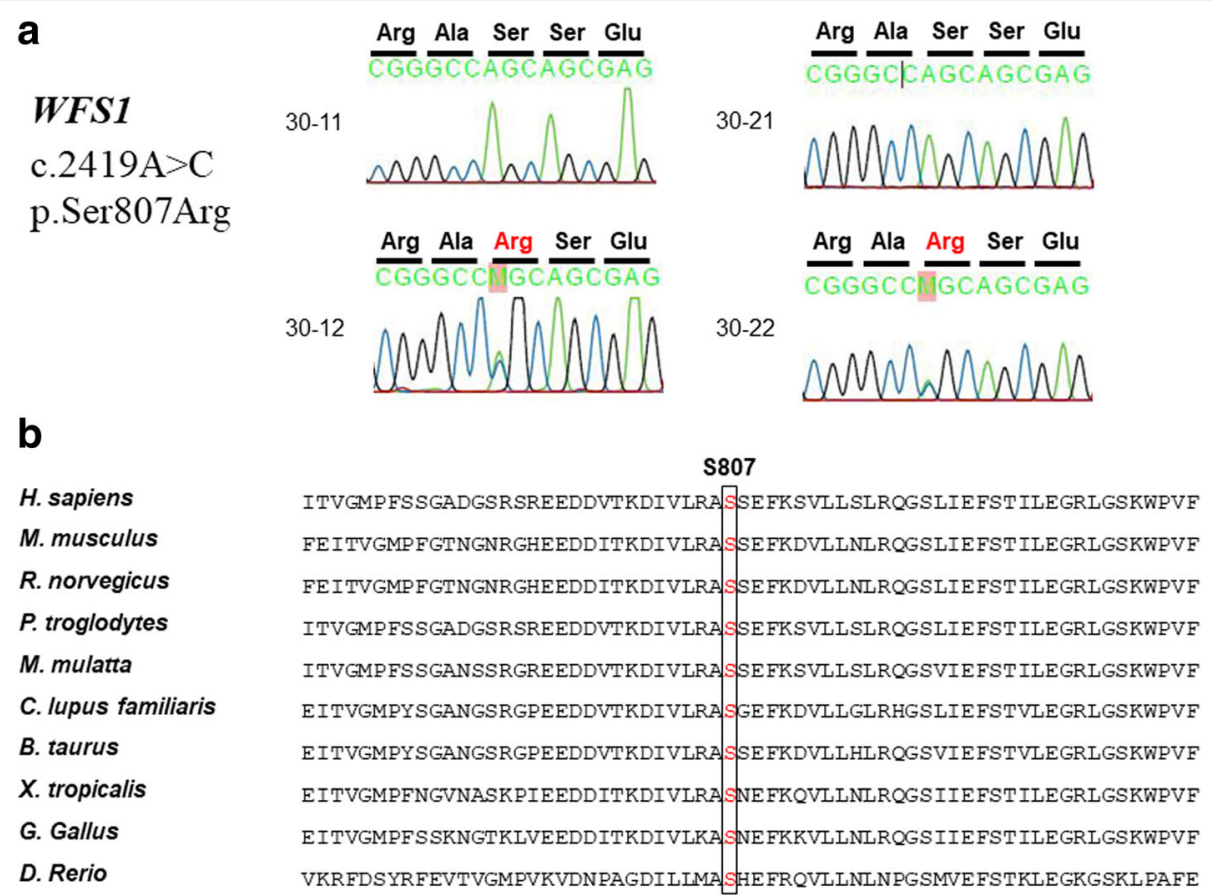

Fig. 2 A mutation in WFS1 identified using whole-exome sequencing. a Sanger sequencing traces of subjects 30-11, 30-12, 30-21, and 30-22. b Multiple sequence alignment of WFS1 among different species. p.S807 is well preserved among various species

Although there are more than 250 mutations in WFS1, some rare mutations have been identified in multiple independent families. In addition, there are only two mutations that span two different ethnic backgrounds: European (p.A716T) and Japanese (p.E864K) [10]. p.S807R was previously reported in a family from the United Kingdom [8]; however, this study is the first to identify and report the mutation in an East-Asian individual. Interestingly, all mutations found in both ethnicities (European and East Asian, including p.A716T, p.E864K, and p.S807R) are located in exon 8, which encodes the C-terminal intracytoplasmic domain. This finding indicates that these mutations may be "hot spot" mutations in exon 8 that span different ethnicities. To convincely tell the mutation is a founder mutation (the result of admixture of two ethnics) or a hot spot, it would be helpful to to compare haplotypes of our patients and British patients.

The majority of mutations associated with LF-NSHL are, in fact, missense mutations located in exon 8 , whereas those linked to Wolfram syndrome are frameshift and nonsense mutations $[7,8,10]$. The mutations responsible for LF-NSHL do not inactivate WFS1 and are presumed to have a dominant-negative effect on the normal WFS1 protein, consistent with an autosomal dominant type of inheritance. Because the $\mathrm{S} 807$ residue is located in the Cterminal domain, the missense mutation at p.S807R affects only a limited number of functions. Although the physiological role of WFS1 in the inner ear remains unknown, mutations, such as p.S807R, only partially disrupt the function of WFS1; thus, hearing loss may not necessarily progress to profound deafness.

Mutations in WFS1 are associated with LF-NSHL. Given that p.S807R was previously found in individuals of European ethnicity, p.S807R may be a hot-spot mutation in WFS1. Because the majority of mutations in WFS1 associated with LF-NSHL are located in exon 8, screening exon 8 should be considered first in genetic analyses of patients with LF-NSHL.

\section{Abbreviations \\ LF-NSHL: Low-frequency nonsyndromic hearing loss; WES: Whole-exome sequencing; WFS1: Wolfram syndrome 1}

\section{Funding}

This work was supported by the Korea Health Technology R\&D Project, Ministry of Health \& Welfare, Republic of Korea (HI16C0142 to J.J.) and the Soonchunhyang University Research Fund (L.J.D.).

\section{Availability of data and materials}

The datasets used and/or analyzed during the current study are available from the corresponding author on reasonable request.

\section{Authors' contributions}

CHJ, LJS, and US performed the experiment and contributed to the acquisition, analysis, and interpretation of data. GHY, CJY, LD, and JJ designed and wrote the manuscript. All authors read and approved the final manuscript. 


\section{Ethics approval and consent to participate}

This study was granted ethical approval from the Institutional Review Board of the Severance Hospital, Yonsei University (Seoul, South Korea) Health System (IRB\#4-2015-0659). All procedures were performed after obtaining informed written consent in accordance with the ethical standards of the institutional research committee and with the 1964 Declaration of Helsinki and its later amendments or comparable ethical standards

\section{Consent for publication}

Written informed consent was obtained from the patient for publication of this research.

\section{Competing interests}

The authors declare that they have no competing interests.

\section{Publisher's Note}

Springer Nature remains neutral with regard to jurisdictional claims in published maps and institutional affiliations.

\section{Author details}

'Department of Otorhinolaryngology, Brain Korea 21 PLUS Project for Medical Sciences, Yonsei University College of Medicine, Seoul 03722, South Korea. ${ }^{2}$ Department of Pharmacology, Brain Korea 21 PLUS Project for Medical Sciences, Yonsei University College of Medicine, Seoul 03722, South Korea. ${ }^{3}$ Department of Otorhinolaryngology, Soonchunhyang University College of Medicine, Bucheon, South Korea. ${ }^{4}$ Yonsei University College of Medicine, 134 Sinchon-dong, Seodaemun-gu, Seoul 120-752, South Korea.

\section{Received: 3 July 2017 Accepted: 8 December 2017}

\section{Published online: 19 December 2017}

\section{References}

1. Bespalova IN, Van Camp G, Bom SJ, Brown DJ, Cryns K, DeWan AT, et al. Mutations in the Wolfram syndrome 1 gene (WFS1) are a common cause of low frequency sensorineural hearing loss. Hum Mol Genet. 2001;10(22):2501-8.

2. Van Camp G, Kunst H, Flothmann K, McGuirt W. Wauters J, Marres H, et al. A gene for autosomal dominant hearing impairment (DFNA14) maps to a region on chromosome $4 \mathrm{p} 16.3$ that does not overlap the DFNA6 locus. J Med Genet. 1999;36(7):532-6.

3. Bodoor K, Batiha O, Abu-Awad A, Al-Sarihin K, Ziad H, Jarun Y, et al. Identification of a novel WFS1 homozygous nonsense mutation in Jordanian children with Wolfram syndrome. Meta Gene. 2016;9:219-24.

4. Rigoli L, Lombardo F, Di Bella C. Wolfram syndrome and WFS1 gene. Clin Genet. 2011;79(2):103-17.

5. Rendtorff ND, Lodahl M, Boulahbel H, Johansen IR, Pandya A, Welch KO, et al. Identification of p.A684V missense mutation in the WFS1 gene as a frequent cause of autosomal dominant optic atrophy and hearing impairment. Am J Med Genet A. 2011;155A(6):1298-313.

6. Jung J, Lee JS, Cho KJ, Yu S, Yoon JH, Yung Gee H, et al. Genetic predisposition to sporadic congenital hearing loss in a pediatric population. Sci Rep. 2017:7:45973.

7. Cryns K, Pfister M, Pennings RJ, Bom SJ, Flothmann K, Caethoven G, et al. Mutations in the WFS1 gene that cause low-frequency sensorineural hearing loss are small non-inactivating mutations. Hum Genet. 2002;1 10(5):389-94.

8. Qian X, Qin L, Xing G, Cao X. Phenotype prediction of pathogenic nonsynonymous single nucleotide polymorphisms in WFS1. Sci Rep. 2015;5:14731.

9. Inoue H, Tanizawa Y, Wasson J, Behn P, Kalidas K, Bernal-Mizrachi E, et al. A gene encoding a transmembrane protein is mutated in patients with diabetes mellitus and optic atrophy (Wolfram syndrome). Nat Genet. 1998; 20(2):143-8

10. Fukuoka H, Kanda Y, Ohta S, Usami S. Mutations in the WFS1 gene are a frequent cause of autosomal dominant nonsyndromic low-frequency hearing loss in Japanese. J Hum Genet. 2007;52(6):510-5.

11. Lynch ED, Lee MK, Morrow JE, Welcsh PL, Leon PE, King MC. Nonsyndromic deafness DFNA1 associated with mutation of a human homolog of the drosophila gene diaphanous. Science. 1997:278(5341):1315-8.

12. Choi BY, Park G, Gim J, Kim AR, Kim BJ, Kim HS, et al. Diagnostic application of targeted resequencing for familial nonsyndromic hearing loss. PLoS One. 2013;8(8):e68692.

\section{Submit your next manuscript to BioMed Central and we will help you at every step:}

- We accept pre-submission inquiries

- Our selector tool helps you to find the most relevant journal

- We provide round the clock customer support

- Convenient online submission

- Thorough peer review

- Inclusion in PubMed and all major indexing services

- Maximum visibility for your research

Submit your manuscript at www.biomedcentral.com/submit
) Biomed Central 